\title{
SASKATCHEWAN'S PELICANS AND CORMORANTS IN 1978
}

KEITH RONEY, Saskatchewan Museum of Natural History, Regina, Saskatchewan, S4P 3V7.

An aerial censusing technique was employed to check the status of White Pelican and Double-crested Cormorant colonies in Saskatchewan in 1978. Eleven colonies with 12,279 pelican nests and 3,967 cormorant nests were censused. This indicated an increase for both species over 1976. This increase, however, was due largely to bias caused by the different survey method used. A standardized method is essential to remove these biases.

Disturbance is a factor that one must always be conscious of when dealing with delicate colonial-nesting species such as White Pelican and Double-crested Cormorant. It has been the major cause of decline in the number of pelican and cormorant nests at several colonies.23459 Therefore, when one engages in a study of these two species, techniques must be used which would eliminate disturbance or at least keep it as low as possible. Gull predation is constantly a problem but is enhanced when coupled with human disturbance. It has been stated "that cormorants appear to hold their own against the gulls except when disturbed from their nests by human visitors". 5

However, when one is conducting surveys, the results are often difficult to compare those of other years if different survey methods are used. Sources of bias can include: 1 . Different times of year; 2. Different times of day; 3 . Different vehicles for survey, e.g., ground or air; 4 . If aerial survey, was the data taken visually or from aerial photographs? If visually, what was the experience of the observers? If by use of photographs, what type of photographic technique and equipment were used? 5. If air survey, different altitudes; 6 . Different weather conditions during the survey.

These are just a few of the possible biases but they give some idea of what must be kept in mind when conducting surveys in order to obtain as comparable counts as possible.

During the 1978 survey, a method was developed that could be standardized and used in the future by other researchers. Included was an aerial photography technique which is not new, but parameters for conducting the survey were established. Standardization would reduce and remove many biases. At the same time, this particular method would reduce the amount of disturbance and mortality of eggs and young caused by a ground survey.

\section{Methods}

Aerial photographs were taken of all but one of the colonies to determine the number of incubating adults and, thereby, the number of nests at each colony.

The aerial survey was conducted from 19 through 29 May. Survey time ranged from 0745 to 0915 (Central Standard Time) when colony activity, such as feeding and nest relief, are minimal. ${ }^{7}$ This provides for easier recognition and calculation of incubating adults from the photos. Cessna 172's and 182's were used to fly the surveys and photographs were taken out the window using a handheld Pentax KX camera with $200 \mathrm{~mm}$ lens. Ektachrome color slide film (ASA 64) was used. All photos were 


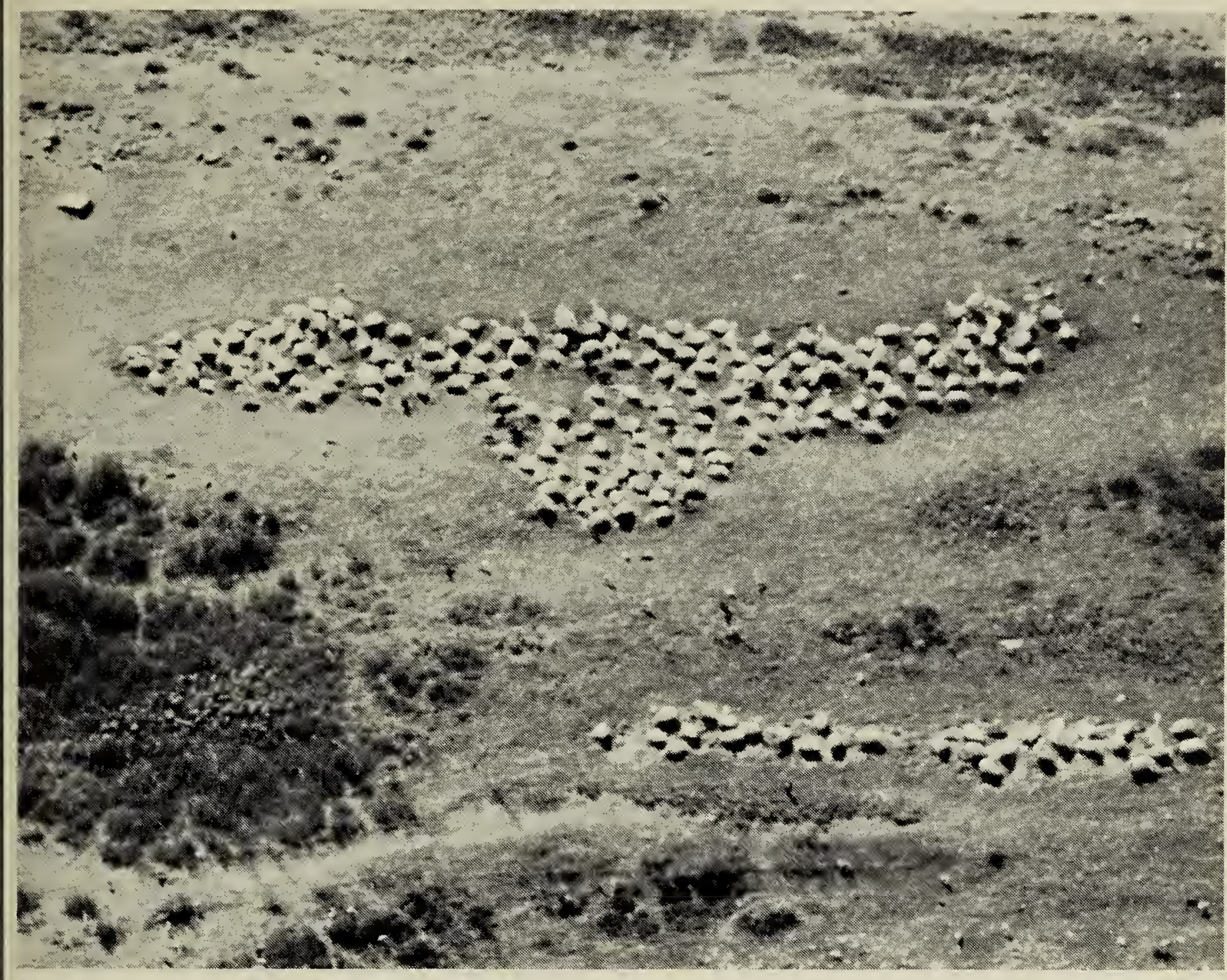

Nesting Pelicans at O/d Wives Lake.

Keith Roney

shot at $230 \mathrm{~m}$ (750 feet) above ground level. This altitude produced no disturbance to colonies. The Cypress Lake colony was checked from the ground as the island is large and hilly enabling one to land and make observations without disturbing the birds.

With a few revisions, this aerial survey method was previously used in Saskatchewan by Boeker who censused six pelican colonies in 1971 and by Trottier and Breneman who censused the Lavallée Lake colony. ${ }^{18}$

Counts were taken directly from the slides while viewing them under a compound microscope.

\section{Results and Discussion}

A total of 12,279 pelican nests at seven colonies were counted (Table 1). This number was more than double the 5,853 nests in $1976 .{ }^{6}$ All colonies showed an increase with the exception of Redberry Lake, where the number of nests decreased from 89 to 72 .

Eleven cormorant colonies were censused and they increased from 3,044 nests in 1976 to 3,967 in $1978 .{ }^{6}$ As with the pelicans, most cormorant colonies showed increases (Table 1). Three colonies experienced a decrease: Kazan Lake suffered the most, dropping from 1,300 to 753 nests, while Quill Lake decreased from 267 to 72 nests and Redberry Lake from 29 to 24 nests. The 1976 figures included the nest data for Lavallée Lake in $1975 .^{\circ}$

The significance of the large increase in the number of pelican nests is difficult to assess because of the bias created by different survey methods. In order to obtain a more accurate comparison of data with that of previous years, a standardized survey method should be established 
TABLE 1 - Aerial counts of Saskatchewan pelican and cormorant colonies in 1978

Location

1. Cypress Lake*

2. Old Wives Lake

3. Last Mountain Lake

4. Redberry Lake

5. Quill Lake

6. Suggi Lake

7. Lavallée Lake

8. Doré Lake

9. Primrose Lake

10. Kazan Lake

11. Churchill Lake

* Ground survey.

and used year after year with revisions made only as is deemed beneficial to increase the accuracy of the data.

Trottier and Breneman, in their study of the Lavallée Lake colony, presented some guidelines for conducting an aerial survey of pelican and cormorant colonies. In addition to the hours, altitude and camera equiment of the present survey, they also suggested: 1 . Survey be conducted at peak of nesting period usually around the first week in June. 2. Survey be conducted on bright sunny days to provide for better picture resolution.

The most important factors are time of year, time of day, and altitude of survey.

\section{Acknowledgeíments}

The assistance of Ben Rosser during the field survey was greatly appreciated. Thanks are extended to Mr. Bruce Wilson, Superintendent of Prince Albert National Park, for granting permission to survey the Lavallée Lake colony. The cooperation and assistance of Department of Tourism and Renewable Resources personnel was appreciated. Appreciation is also extended to the many pilots involved in the survey.

$\begin{array}{cc}\begin{array}{c}\text { Pelican } \\ \text { Nests }\end{array} & \begin{array}{c}\text { Cormorant } \\ \text { Nests }\end{array} \\ - & 395 \\ 3,084 & 658 \\ - & 337 \\ 72 & 24 \\ 232 & 72 \\ 913 & 579 \\ 3,019 & 651 \\ \overline{-} & 270 \\ 4,007 & 124 \\ 952 & 753 \\ - & 104 \\ 12,279 & 3,967\end{array}$

'BOEKER, E. L. 1972. A survey of White Pelican nesting Colonies in 1971. Am. Birds 26:24, 125.

${ }^{2}$ CARSON, R. D. 1966 . Destruction of colonial birds on an island on Suggi Lake. Blue Jay 24:96-97.

${ }^{3}$ ELLISON, L. N., and L. CLEARY. 1978. Effects of human disturbance on breeding of Double-crested Cormorants. Auk 95:510-517.

4JOHNSON, R. F., and N. F. SLOAN. 1976. The effects of human disturbance on the White Pelican colony at Chase Lake National Wildlife Refuge, North Dakota. Inland Bird Banding News 48:163-170.

5KURY, C. R., and M. GOCHFELD. 1975. Human interference and gull predation in cormorant colonies. Biol. Conserv. 8:23-34.

${ }^{6}$ RONEY, K. 1978. Pelicans, Cormorants and Great Blue Herons in Saskatchewan in 1976. Blue Jay 36:28-35.

${ }^{7}$ SCHALLER, G. B. 1964. Breeding biology of the White Pelican at Yellowstone Lake, Wyoming. Condor 66:3-23.

${ }^{8}$ TROTTIER, G., and R. BRENEMAN. 1976. Population status and foraging distribution of White Pelicans breeding in Prince Albert National Park, Saskatchewan. Can. Wildl. Serv. Rep. Unpubl.

${ }^{9}$ VERMEER, K. 1970. Distribution and size of colonies of White Pelicans (Pelecanus erythrorhynchos) in Canada. Can. J. Zool. 48:1029-1032. 